\title{
Hipsters on our High Streets: consuming the gentrification frontier
}

\author{
Phil Hubbard, Professor of Urban Studies, SSPSSR University of Kent
}

\begin{abstract}
:
Gentrification involves the displacement of working class populations, a phenomena most obviously manifest in the transformation of residential landscapes. But this is also palpable in the changes visible on many shopping streets, with locally-oriented stores serving poorer populations and ethnic minorities being replaced by 'hipster' stores such as 'real coffee' shops, vintage clothing stores and bars serving microbrews. These stores have been taken as a sign that the fortunes of struggling shopping streets are improving, with the new outlets often depicted as offering a better range of healthy, green and 'authentic' consumption choices than the shops they displace. However, this paper argues that we need to resist this form of retail change given it typically represents the first stage of a more thoroughgoing retail gentrification process, remaining suspicious of forms of hipster consumption which, while aesthetically 'improving' local shopping streets in deprived areas, actually encourage the colonisation of neighbourhoods by the more affluent.
\end{abstract}

Keywords: gentrification, urban policy, retail, class conflict, hipsters.

\section{Introduction}

While many studies of consumption focus on the spectacular and new, there's been an increasing recognition that 'ordinary' shopping streets providing a mix of independent, ad hoc and 'ethnic' retailing can help support and sustain ethnically diverse and comparatively deprived populations (Hall, 2011). Brick Lane in the east end London borough of Tower Hamlets is no exception. Over the last forty years or so, it's been largely shunned by corporate retail capital, but has developed a relatively resilient range of halal butchers, mobile phone shops, curry houses and grocers, many run by members of the Bangladeshi diaspora who arrived in the early 1970s. But since the late 1990s, Brick Lane's cosmopolitan mix of restaurants and grocery stores has been slowly transforming as more trendy, artful types have descended on this 'edgy' corner of the metropolis, with pop-up food trucks, 'real' coffee shops and splashes of street-art encouraging an incipient gentrification process that has pushed up retail rents and forced some Bangladeshi businesses to close (Mavrommatis, 2010).

In this context, the 2014 opening of the Cereal Killer Café on Brick Lane by a pair of white entrepreneurs from Dublin attracted critical headlines, with media commentators mocking its business model of selling imported US breakfast cereals 
at premium prices in a borough where $49 \%$ of children in live in poverty, many going without breakfast at all http://www.dailymail.co.uk/news/article-

2869969/Excruciating-encounter-hipster-twin-Cereal-Killer-cafe-challenged-sellingbowl-cornflakes-3-20-one-London-s-poorest-areas.html). This attack encouraged

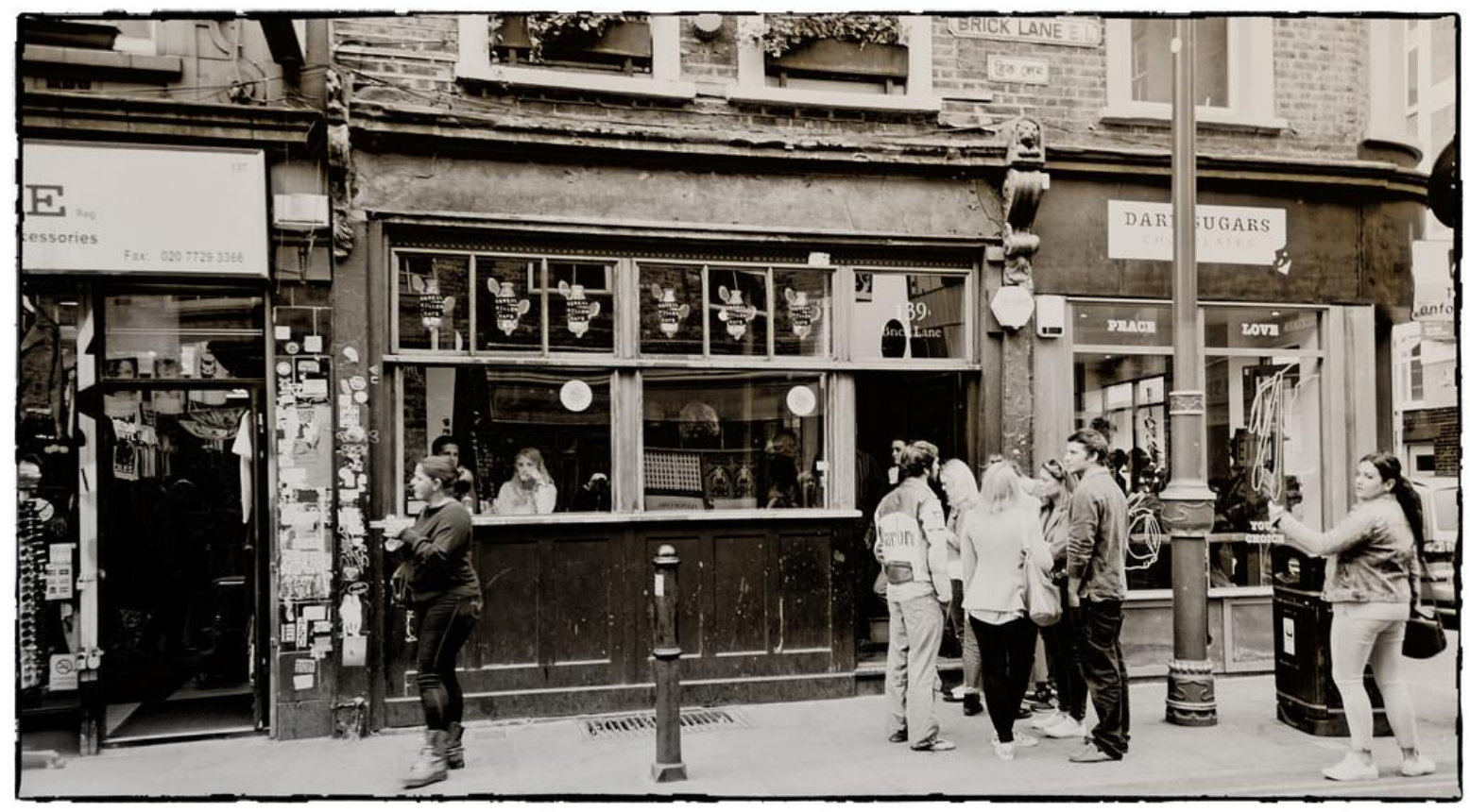

Figure One: Cereal Killers café (credit: Jack Torcello, creative commons)

Boris Johnson, Mayor of London, to weigh in with his defence, suggesting that the press had 'monstered' the owners - 'a gentle pair of bearded hipsters' - for their 'pretensions to gentrify the area', and were not 'right to do so'. In his view, 'It is a great thing to want to open a place of work in one of the poorest boroughs in Britain. We don't need taxpayer-funded journalists endlessly bashing the wealth-creators of this country, and sometimes we need to be a little less cynical and a bit more encouraging' (http://www.telegraph.co.uk/comment/11293491/Dont-murder-theCereal-Killers-we-need-people-just-like-them.html). Yet such appeals did not prevent the café being attacked in a September 2015 Class War street demonstration ('Fuck London'), which reportedly had encouraged participation via a Facebook post proclaiming 'We don't want pop-up gin bars or brioche buns - we want community' http://www.theguardian.com/uk-news/2015/sep/27/shoreditch-cereal-cafetargeted-by-anti-gentrification-protesters). Red paint and cereal was daubed on the windows, as the crowds shouted 'scum' at the owners and frightened clientele.

In the wake of this there has been sustained discussion as to whether this 'hipsterrun' business should bear the brunt of the anger of those who feel our cities are being taken away from working class communities. For every person condemning the shop for driving the gentrification frontier further into WC neighbourhoods (http://www.theguardian.com/commentisfree/2015/sep/28/cereal-killer-cafeprotest-gentrification-poverty), it seems there were others leaping to their defence, proclaiming that independent businesses like the Cereal Killer Café are actually the 
last bastion holding out against big businesses encroaching on the East End http://www.theguardian.com/commentisfree/2015/sep/27/hipster-cereal-killercafe-gentrification-east-end). And this debate is not one isolated to Brick Lane. Elsewhere in the East End, for example, the Asian Women's Advisory Centre on Mare Street, Hackney, has been transformed into The Advisory diner (http:/ / dalstonist.co.uk/the-advisory-diner-apologises-over-womens-centrebranding-row/), while south of the river, the Job Centre on Deptford's High Street has been transformed into a 'post-industrial' bar serving craft beers http://www.theguardian.com/commentisfree/2014/jul/09/job-centre-bargentrification-ironically-deptford). Such obvious and 'ironic' transformation of premises that used to cater for the needs of local, working class and vulnerable people has spurred further vilification of hipsters, and provoked numerous protests against the trendy, new businesses that are seen to be taking over formerly working class areas (http://www.swlondoner.co.uk/campaigners-set-for-protest-againstnew-champagne-bar-in-brixton-village/). This is repeated beyond the UK, with 'hipster neighbourhoods' including Williamsburg, New York, Kreuzberg, Berlin and Sydney's inner West witnessing similar controversies and acts of resistance (Drisel, 2011).

So are hipsters entrepreneurial urban pioneers or exploitative parasites? Or both? Much debate has raged in the media about whether hipsters should be read as a symptom of gentrification, or causal agents. But gentrification is nothing but complex. Academic perspectives attentive to both structure and agency would insist that hipster incomers are involved in the refiguring of local taste cultures which is encouraging processes of displacement, but would argue they are not solely to blame for the processes making neighbourhoods unaffordable for the less affluent. This might imply that rather than pillorying hipsters we need to critique the local authority policies that are currently encouraging the displacement of existing working class communities, particularly via strategies of stock transfer and the redevelopment of council estates by private developers (Lees 2014). But is this to let hipster gentrifiers themselves off the hook? After all, corporate and state-led gentrification relies on a steady stream of young professionals, trendy urbanites and creatives prepared to pay a premium to live in previously 'devalued' working class districts, and these groups are often explicit about their desire to buy into 'gritty', authentic metropolitan cultures. Whether consciously or otherwise, when any middle class incomers establish themselves on the 'gentrification frontier' they fundamentally change the character of place, inducing displacement pressures that can have long-term consequences for those working class residents they co-locate with. But can the hipster really be understood as akin to other middle class incomer groups? And does hipster urbanism in the form of independent coffee shops, vinyl record stores and craft beer burger joints really destroy the character of multi-ethnic inner city shopping streets?

\section{The hipster: friend or foe?}


In sociological terms, the 'hipster' remains poorly defined, an urban 'type' often invoked in contemporary analyses of cultural change in the city (e.g. Lloyd, 2010; Zukin, 2011), but rarely delineated as a distinct cultural identity. This is perhaps not surprising, as the hipster is perhaps best understood not as a distinctive selfproclaimed identity but a pejorative term used to describe a post-critical, ironic and possibly ideologically bankrupt mode of consumption (Schiermer, 2014). This said, some have attempted to define hipsters indexically though their adoption of styles that exist in opposition to mainstream consumer culture, something particularly manifest in a valorisation of 'authentic' vintage goods, kitsch retro styles and artisanal production (Michael 2015). Flannel-shirted, flat white-coffee consuming bearded hipsters are also indelibly associated with urban life, being found in the neighbourhoods taken to embody cosmopolitan and metropolitan values: the hipster evidently eschews the drab conformity of the suburbs and the serialised landscapes of out of town consumption.

So in this sense, the hipster is an ambivalent figure, urban yet pitched against the values of the consumer city, dismissive of fashions but also highly fashionable. However, we would do well to remember that the ironic consumption of working class culture, the kitsch and the retro is not something that is affordable to all. 'Poor chic' does not involve the simple purchase of, and display, of second hand or discount goods. It requires serious disposable income to clean and restore such goods, turning the merely shabby into 'shabby chic'. Working class authenticity is cherished, but in the process it's symbolically consumed until little trace of its 'dirty' working class background remains. When hipsters move into previously devalued or working class spaces, the results are then often immediately apparent in aesthetic changes and 'improvements' to the locality, and these are ones that can involve forms of symbolic violence as the hipster habitus comes to dominate.

This said, many hipsters appear active in a form of DIY activism and urban improvement that many deprived shopping streets are crying out for. Hipster urbanism, for example, can be manifest in the creation of bike lanes, new pocket parks and public artworks (Douglas, 2014). And while hipsters appear rich in cultural and educational capital, they are seldom part of the super-rich elite, being more routinely described part of the precariat (McGuigan, 2016). In this sense, we might describe hipsters as benevolent urban neo-tribe intent on improving the appearance of many inner city districts through knowing, playful and aestheticallyastute interventions which are not driven by a strong profit-motive. Working class residents are not always resentful of these changes given they can enhance senses of community pride (Paton, 2010). Likewise, new hipster businesses can diversify the range of goods and services available on some local shopping streets, and existing independent traders and businesses can be welcoming of these in instances where they are more in keeping with the local business ethos than multiple chains like Starbucks or Subway. Far from being a sign of gentrification, the emergence of hipster businesses in deprived places could be viewed as a grass-roots form of urban change that is actually resistive to corporate gentrification. 
So are hipsters 'pioneer' gentrifiers or not? It's here that we might usefully learn from previous academic research focusing on the 1980s yuppie, the gay gentrifier, the artist-gentrifier and so on. For example, it's well known that artists were deliberately used as avant-garde gentrifiers ('scuzzers') by real estate agents in the 1990s as they sought to push prices upwards in Hoxton, a mainly working class district immediately north of the financial district of the City of London. This area became home to a rich variety of trendy restaurants, boutiques, and pubs where artists mixed with media creatives, students and Britpop musicians, spawning an arts scene based around notable galleries and clubs. While this regeneration was, as Andy Pratt (2011) details, at best partial and selective, there's little question arts-led transformation turned much of this down-at-heel and marginalised district into a highly desirable residential and commercial location: ultimately, this pushed the artists out as studio rents and accommodation costs spiralled.

Andrew Harris (2012) concludes that Hoxton's story shows there is a 'field of gentrification' in which the cultural capital developed by artists through their 'valorisation of the mundane' is subsequently appropriated by market forces leading to the subsequent displacement of artists to cheaper districts. This is an interpretation that leans on David Ley's (2003) studies in Vancouver, Canada, where the perceived uplift of many older, inner city neighbourhoods started via the emergence of artistic and 'bohemian' stores. However, Ley suggested this quickly linked to other forms of 'creative capital', such as those associated with advertising, architecture and publishing. Within a few short years, this created a local service economy almost entirely oriented to upper middle class populations, and one no longer affordable to artists. Like Harris, Ley (2003: 2541) depicts artists as victims of gentrification, suggesting that it is the 'societal valorization of the competencies of the artist that subsequently attracts followers richer in economic capital'.

This literature suggests that artists rarely operate consciously as developers or gentrifiers themselves, with their locational strategies merely reflecting their search for affordable living and work spaces in an interesting neighbourhood. This said, it has been repeatedly shown that artists create little oases of cool in the inner city, slowly pushing away the ethnic and class diversity that makes such areas affordable in the first place. The presence of artists - particularly visual artists - is then a catalyst for neighbourhood transition, converting ' urban dilapidation into ultra chic' (Smith 1996: 18). Here, both the visible presence of the arts (e.g. the emergence of gallery and studio spaces) and the reputational change associated with this (e.g. the caché attached to artistic lifestyles) transforms the symbolic meaning of urban spaces and encourages exploitation of the 'rent gap'. This confirms that 'promotion of the creative class, and its habitus, if not actively checked, is a de facto support for a particular type of gentrification, and an implicit, or often explicit, (re-)ordering of social and cultural priorities' (Pratt 2011: 296). But do hipster businesses on British High Streets really fulfil the same function?

\section{Hipster businesses at the gentrification frontier}


In the wake of the 'regeneration maelstrom' enveloping London following the 2012 Olympics, its inner city shopping streets have been at the centre of debates concerning the transformation of the 'local' and 'authentic' into consumer spectacle. The emergence of new hipster cafes and pop-up eateries have been important here, but so too has been the re-development of many traditional street markets by the local councils that run them. Broadway market (Haggerston, Hackney), Borough market (London Bridge, Southwark) and Chatsworth Road market (Lower Clapton Hackney) have all been transformed beyond recognition, and others remain threatened (e.g. the proposed redevelopment of the ad hoc retail under the Brixton railway arches, South London, as 'Atlantic Road Village' http://www.brixtonbuzz.com/2016/02/brixton-arch-traders-given-six-months-toleave-as-redevelopment-planning-application-is-submitted/). The model here is one that replaces an economy of necessity and thrift with one of distinction and display: as Gonzalez and Dawson (2015: 21) document, the idea of a market as a gastronomic destination has been emphasized in market redevelopment, meaning 'essential goods such as affordable fresh fruit, vegetables, meat and fish become secondary or disappear'. Crucially, while these markets were previously spaces of working class sociality, as well as economic reproduction, their transformation has been widely celebrated in policy circles, seen to have restored the fortunes of shopping streets previously regarded as cheap, dirty, and backwards. Witness, for example, Mary Portas' (2011) government-commissioned review of the British High Street (http:/ / www.maryportas.com/wp-content/uploads/The_Portas_Review.pdf): though intended to address the obvious problems of vacant premises on many local shopping streets, the recipe for retail revival espoused in her report is one

privileging up-market Farmer's Markets, craft production, and 'pop-up' galleries over the type of consumption that might actually thrive in less affluent communities (see Hubbard 2016).

While the role of retail change in prompting gentrification is not much acknowledged in the UK, in the US, the phenomenon is better understood, with the replacement of corner cafés by coffee shops, convenience 'ethnic' grocery stores by delis and pubs by wine bars often depicted as a vital first stage in gentrification processes culminating in the up-scaling of entire neighbourhoods. New York-based cultural commentator Sharon Zukin and colleagues have provided one of the most influential accounts of these processes, arguing that the economic and cultural entrepreneurs establishing new retail businesses in previously deprived districts like Williamsburg, Brooklyn sought to fabricate an 'aura of authenticity' based on the working class history of the area. In doing so, they initially capitalized on their reputation among a youthful clientele seeking an authentic alternative to mainstream consumption space, attracting a broader middle class consumer base over time. And, as Zukin et al (2009) note, good write-ups in the local media and word-of-mouth publicity brought more new investors: shoppers, diners, residents, real estate developers, and retail entrepreneurs. In time, rents went up, with the 
synergistic combination of retail and residential gentrification ultimately producing neighbourhoods associated with solidly middle class rituals of belonging. Many longer-term working class residents - especially non-white residents poorly served by new white businesses - were priced out of the neighbourhood, and cast culturally adrift.

But is this an accurate description of what happens when hipster businesses spring up on working class streets in Britain? In part, this type of account doesn't quite fit with the idea of the hipster as promoting a more authentic and even 'local' form of consumption, someone potentially involved in DIY urbanism and authentic placemaking. But, as Ico Maly and Piia Varis (2015) point out, hipster culture is also translocal, with the hipster's search for distinction via authenticity sharing certain characteristics whether in the US, Germany, or UK (with the consumption of 'real' coffee, vintage clothes, microbrews, and indie music appearing central). Through interactions with hipster consumers from elsewhere, and increasing mediation, hipster neighbourhoods are gradually incorporated into global consumer cultures, even if a residuum of local culture survives. To again quote Zukin et al (2009: 52), 'under current conditions of globalization, they provide a material base for new kinds of cosmopolitanism that ignore old expressions of ethnic homogeneity and contrast with cultural forms, including consumption spaces, which embody lowstatus identities'.

So while hipster stores exude authenticity and celebrate local distinctiveness, they are inevitably caught up in processes that valorize particular neighbourhoods. Here, literatures on 'global gentrification' demonstrate that local character is a highly marketable commodity in place promotion, but one seldom associated with immigrant or 'ethnic' neighbourhoods per se (Bridge, 2007). Rather, what sells is a form of consumption in which knowledgeable white entrepreneurs turn 'sketchy' neighbourhoods into ones characterised by a more navigable and 'safer' version of cosmopolitanism. Incoming hipster businesses are complicit in this process given they trade on the caché of being in an edgy multicultural neighbourhood, but offer forms of consumption easily intelligible to the white middle class readers of the Sunday supplements and style magazines. This suggests an almost complete enrolment of hipster cultures within an infrastructure of gentrification that involves international lifestyle commentators, restaurant reviewers, and real estate agents discoursing particular neighbourhoods as cosmopolitan and cool.

And herein lies the problem. As Deb Cowen (2006: 22) writes, once upon a time hipsters might have been viewed as pioneer gentrifiers readily displaced the moment people with 'real' financial capital stepped in, today it appears they 'are actively working to institutionalize themselves in the city'. Suggesting 'they have recently found allies in government and business who see possibilities of accumulation by good design', Cowen continues to suggest they have becomes agents of neoliberalism, colonizing the inner city and claiming it as their own through 'banal, mimetic, creativity'. Here, it's worth stressing that while hipsters might espouse certain counter-cultural values, they are generally white and wealthier than than those who reside in the multi-cultural and working class 
communities they have occupied. Interpreted this way, we should not regard the emergence of cosmopolitan hipster businesses in working class areas as a prelude to gentrification, but see it as a form of gentrification in itself.

\section{Conclusion}

Writing from the perspective of a middle class academic, it is difficult to be objective about the arrival of hipster stores on previously struggling shopping streets. On the surface, such stores appear authentic and meaningful, not banal and serially replicated, and many espouse values of authenticity, locally-based production and craft which respect working class traditions. Hipster bars favour microbrews and real ale over mass-produced, imported lagers; wholefood shops eschew fast food cultures in favour of exotic, 'ethnic' and 'green' foodstuffs; and vintage clothing stores represent a welcome reaction to sweat-shop, disposable fashions. There's also a resolute focus on durable goods rather than the transient or immaterial (e.g. the vinyl record over the mp3, the book over the kindle). But - make no mistake - the presence of one-off hipster stores marks out a shopping street as being up-to-date and on-trend, a form of distinction that is highly valued in consumer society. So while there are undeniable pleasures to be taken in consuming hipster-stores, and using these to enhance one's own sense of individuality and self-expression, it's vital to remember these are pleasures limited to those who have sufficient capital to do so. Consuming these spaces supports gentrification, pure and simple.

In writing this I am not arguing that the middle classes should shun declining or less affluent inner city districts, or that we should always classify the hipster as a middle class agent of gentrification (noting the dangers of misidentification that this would imply: see Tyler, 2015). It is too easy for middle class academics to demonize hipsters when there are a variety of white and non-white middle class groups equally complicit in gentrification. But I think it is vital to critique - and expose - policy instruments that promote a cosmopolitan, hipster-led model of retail gentrification as the way of regenerating 'failing' shopping streets. This is something that might involve us reconsidering the 'value' of those shopping streets depicted as failing, and recognising that the last thing they need is the arrival of shabby chic hipster stores, galleries and pop-up eateries. As Suzanne Hall (2011: 2575) has argued many local shopping streets described as 'distressed' actually 'exhibit a relative economic and cultural vibrancy despite being located within areas of relatively high deprivation'. These boast plenty of stores which the hipster might frequent in their search for a unique and authentic style, but also serve local, working class populations pretty well with their variety of 'ethnic' foodstores, chemists, convenience stores, phone shops, bookmakers, money-lenders, nail bars, pubs, and chicken shops. Some of these businesses fall well outside official visions of what a 'good' shopping street should contain, but they create jobs, and offer affordable diversion and leisure, adding to neighbourhood vitality even if they are frowned on by Mary Portas and others who seem to consider that premises like discount stores, 'ethnic' shops and fast food takeaways are inferior to boutiques, art galleries and hipster cafés. 


\section{References}

BRIDGE, G. (2007). A global gentrifier class?. Environment and Planning A, vol. 39, no. 1, p. 32-46.

COWEN, D. (2006) Hipster urbanism. Relay: A Socialist Project Review, vol 13, p. $22-$ 23.

DOUGLAS, G. (2014) Do- It- Yourself Urban Design: The Social Practice of Informal "Improvement" Through Unauthorized Alteration. City \& Community, vol. 13, no. 1, p. 5-25.

DRISSEL, D. (2011) Anarchist Punks Resisting Gentrification: Countercultural Contestations of Space in the New Berlin. International Journal of the Humanities, vol. 8 , no. 10, p. $19-44$.

GONZALEZ, S. and Dawson, G. (2015) Traditional markets under threat: why it's happening and what traders and customers can do.

http://tradmarketresearch.weebly.com/uploads/4/5/6/7/45677825/traditional_m arkets_under_threat-_full.pdf

HALL, S.M. (2011) High Street adaptations: ethnicity, independent retail practices, and localism in London's urban margins. Environment and Planning A, vol. 43, no. 11, p. $2571-2588$.

HARRIS, A. (2012) Art and gentrification: pursuing the urban pastoral in Hoxton, London. Transactions of the Institute of British Geographers, vol. 37, no. 2, p. 226-241.

HUBBARD, P. (2016) The Battle for the High Street: retail gentrification, class $\mathcal{E}$ disgust. Basingstoke, Palgrave.

LEES, L. (2014) The urban injustices of new Labour's "New Urban Renewal": The case of the Aylesbury Estate in London. Antipode, vol. 46, no. 4, p. 921-947.

LEY, D. (2003) Artists, aestheticisation and the field of gentrification. Urban Studies, vol. 40, no. 12 , p. 2527-2544.

LLOYD, R. (2010) Neo-Bohemia: Art and commerce in the postindustrial city. London, Routledge.

McGUIGAN, J. (2016) Neoliberal Culture. Basingstoke, Palgrave.

MALY, I. \& Varis, P. (2015) The 21st-century hipster: On micro-populations in times of superdiversity. European Journal of Cultural Studies, Online early, DOI 1367549415597920.

MAVROMMATIS, G. (2010) A racial archaeology of space: A journey through the political imaginings of Brixton and Brick Lane, London. Journal of Ethnic and Migration Studies, vol. 36, no. 4, p. 561-579. 
MICHAEL, J. (2015) It's really not hip to be a hipster: Negotiating trends and authenticity in the cultural field. Journal of Consumer Culture, vol. 15, no. 2, p. 163-182.

PATON, K. (2010) Making working-class neighbourhoods posh? Exploring the effects of gentrification strategies on working-class communities. In: Taylor, Y. (ed.) Classed Intersections: Spaces, Selves, Knowledges. Ashgate: Farnham

PRATT, A. C. (2011) The cultural contradictions of the creative city. City, Culture and Society, vol. 2, no. 3, p. 123-130.

SCHIERMER, B. (2014). Late-modern hipsters. Acta Sociologica vol. 57, no. 2, p. 167181.

SMITH, N. (1996) New Urban Frontier: Gentrification and the Revanchist City. London, Routledge.

TYLER, I. (2015) Classificatory struggles: class, culture and inequality in neoliberal times. The Sociological Review, vol. 63, no. 2, p. 493-511.

ZUKIN, S. (2011) Naked City: the death and life of authentic urban spaces. Oxford, Oxford University Press.

ZUKIN, S., Trujillo, V., Frase, P., Jackson, D., Recuber, T., \& Walker, A. (2009) New retail capital and neighborhood change: boutiques and gentrification in New York City. City \& Community, vol. 8, no. 1, p. 47-64. 